\title{
Intracapsular Carcinoma ex Pleomorphic Adenoma in the Buccal Space: Management Dilemma
}

\author{
${ }^{1}$ Dandekar Mitali, ${ }^{2}$ Chaukar Devendra, ${ }^{3}$ Kane Shubhada, ${ }^{4}$ Juvekar Shashikant \\ ${ }^{5}$ D’Cruz Anil \\ ${ }^{1,2,5}$ Department of Head and Neck Surgery, Tata Memorial Hospital, Parel, Mumbai, Maharashtra, India \\ ${ }^{3}$ Department of Pathology, Tata Memorial Hospital, Parel, Mumbai, Maharashtra, India \\ ${ }^{4}$ Department of Radiology, Tata Memorial Hospital, Parel, Mumbai, Maharashtra, India
}

Correspondence: Chaukar Devendra, Department of Head and Neck Surgery, Tata Memorial Hospital, Dr E Borges Road Parel, Mumbai-400012, Maharashtra, India, e-mail: dchaukar@gmail.com

\footnotetext{
Abstract

Objective: Rare case of intracapsular carcinoma ex pleomorphic adenoma in the buccal space with focus on its appropriate management. Method: Case report with review of current literature on buccal space lesions and intracapsular carcinoma ex pleomorphic adenoma. Result: Although salivary gland tumors are common, intracapsular carcinoma ex pleomorphic adenoma is a rare entity especially within the buccal space with no similar case report in the current literature.

Conclusion: Our case is unusual due to its unusual presentation in the buccal space and pathological features. This case report also highlights issues regarding its appropriate management.

Keywords: Pleomorphic adenoma, salivary gland neoplasm, facial neoplasm.
}

\section{INTRODUCTION}

Carcinoma ex pleomorphic adenoma is an aggressive, poorly understood and rare malignancy with an occurrence of 1.6 of all mixed tumors. ${ }^{1}$ It frequently arises in the major salivary glands presenting as sudden change in a long standing swelling with infiltration in the surrounding structures. Its pathological features and clinical behavior demands aggressive management. Our case was unusual in view of its location, unusual presentation and its intracapsular, focal changes. The management issues of such tumors with focal carcinomatous changes have been highlighted.

\section{SEARCH STRATEGY}

A comprehensive literature search on PUBMED/MEDLINE was performed for salivary gland neoplasms in the buccal space. Keywords used were 'pleomorphic adenoma', 'salivary gland neoplasms' 'facial neoplasms' with a combination of above.

\section{CASE REPORT}

A 50 years old male presented with a right sided cheek swelling of 3 months duration. It was nonprogressive and painless. There was no history of previous surgical intervention. On palpation, the swelling was smooth, nodular, firm, free from the surrounding structures and close to the oral mucosa. Thus, clinically it appeared like a benign tumor in the buccal space. Magnetic resonance imaging was also corroborative revealing a $3.2 \mathrm{~cm}$, moderately vascular, well-encapsulated tumor within the buccal space without any infiltration into the surrounding structures (Fig. 1).

Fine needle aspiration however, suggested a poorly differentiated adenocarcinoma. Hence a wide excision of the tumor was planned. Since it was palpable close to the oral mucosa, an intraoral approach was adopted. Frozen section suggested a pleomorphic adenoma. However, the final histopathology revealed a carcinoma ex pleomorphic 


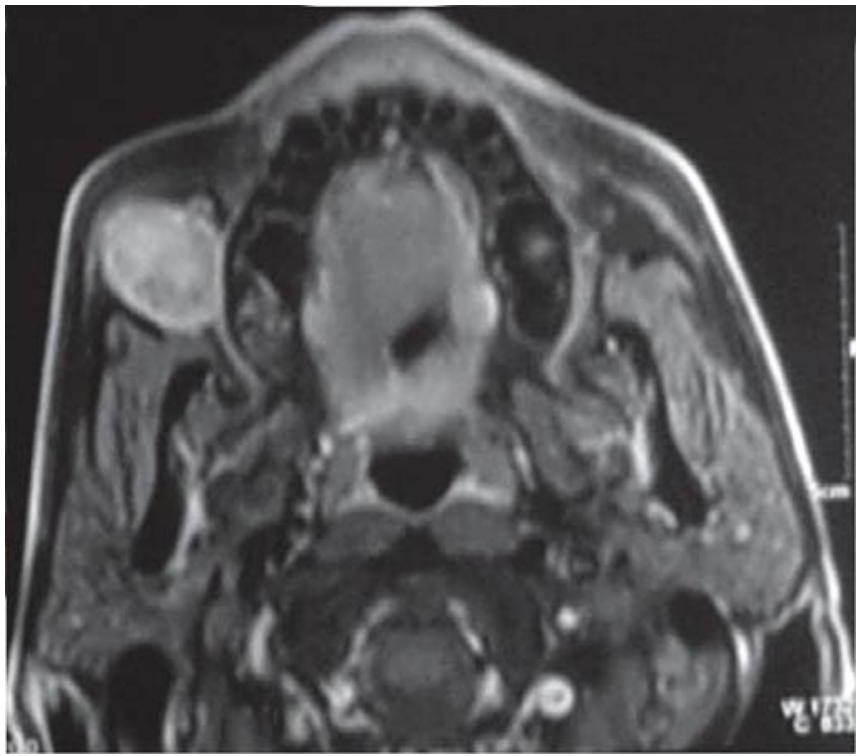

Fig. 1: T1 weighted fat suppression image (postcontrast): Inhomogenous, well-defined, contrast enhancing lesion in the right buccal space on axial image

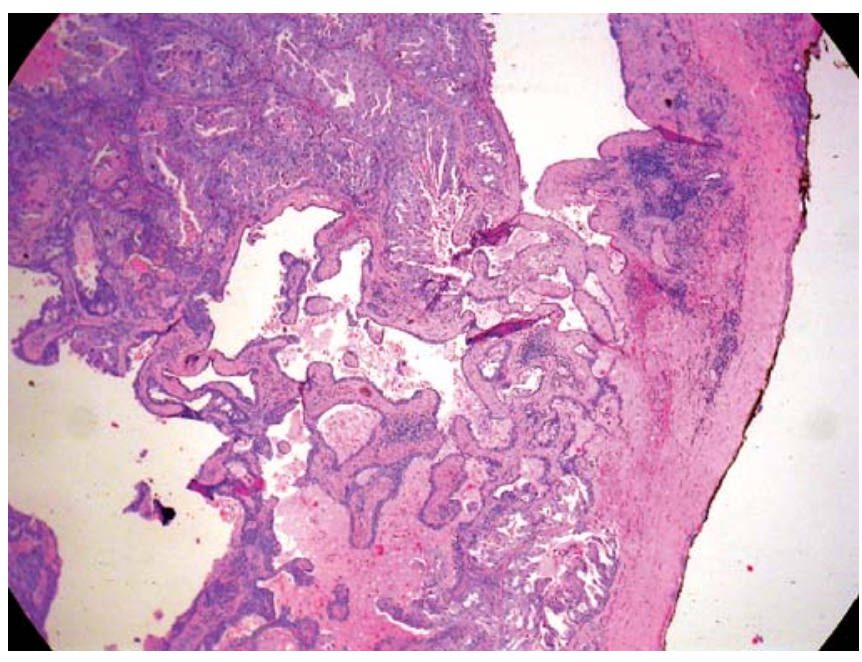

Fig. 2: Well-circumscribed tumor showing benign and carcinomatous component enclosed within a fibrous capsule ( $\mathrm{H}$ and $\mathrm{E}, 2 \mathrm{X})$

adenoma. Since the clinical findings did not corroborate with the histopathology, the slides were reviewed by a senior pathologist. It was found that the histopathology was indeed pleomorphic adenoma with focal intracapsular carcinomatous changes (Figs 2 and 3). Immunohistochemistry stained positively for cytokeratin (CK) and epithelial membrane antigen (EMA). In view of the histopathology suggestive of carcinomatous changes, patient was subjected to adjuvant radiotherapy after a literature search did not suggest any separate management guidelines for intracapsular carcinoma ex pleomorphic adenoma.

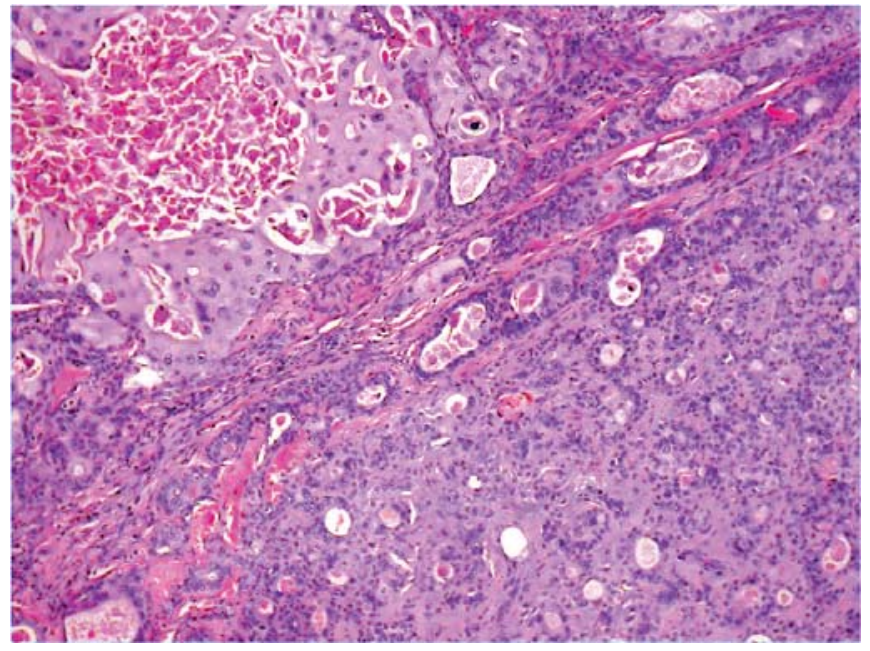

Fig. 3: Slide showing interface between benign pleomorphic adenoma in the right lower and malignant component in left upper corner $(\mathrm{H}$ and $\mathrm{E}, 4 \mathrm{X})$

The patient received radiotherapy in 30 fractions with a dose of 2 grays/ fraction. Patient is loco regionally controlled at one year of follow-up.

\section{DISCUSSION}

Buccal space is confined to the cheek lateral to the buccinator. It was first described in 1935 by Coller and Yglesias. ${ }^{2}$ It is an anatomical compartment lying deep to the zygomaticus major. A greater part of the buccal space is filled by the buccal pad of fat. The other contents include the Stenson's duct, facial and buccal arteries, facial vein and branches of facial and mandibular nerves. Buccal space also has minor salivary glands and accessory parotid glands. ${ }^{2,3}$ The accessory lobe is found in about $20 \%$ of the population within the buccal space, along the line of the Stenson's duct and drains into it. ${ }^{4}$ Common salivary gland tumors within the buccal space are pleomorphic adenomas.

Carcinoma ex pleomorphic adenoma has an infrequent occurrence representing 3 to $5 \%$ of salivary gland neoplasm and 5 to $15 \%$ of salivary gland malignancies. ${ }^{5}$ It occurs most frequently in the major salivary glands especially the parotid. It occurs in recurrent or long standing pleomorphic adenoma as described by Spiro et al. ${ }^{6}$ The duration of the symptoms range from 1 to 48 years. ${ }^{7}$ The usual presentation is that of a long standing mass with sudden increase in size. The patient may also present with signs of infiltration to the surrounding structures. Invasion into the surrounding structures is an important feature in arriving at a diagnosis of malignant mixed tumor. ${ }^{8}$ Such tumors with malignant 
Table 1: Surgical approaches to the buccal space ${ }^{11}$

\begin{tabular}{|c|c|c|}
\hline Approach & Advantage & Drawback \\
\hline Direct/Intraoral & $\begin{array}{l}\text { Elimination of skin incision, limits area of tumor } \\
\text { implantation, eliminates complication of flap necrosis }\end{array}$ & Risk of damage to facial nerve, Stenson's duct \\
\hline Direct cutaneous & $\begin{array}{l}\text { Limits area of tumor implantation, eliminates } \\
\text { complication of flap necrosis }\end{array}$ & Visible scar, limited exposure \\
\hline Preauricular & Provides access to lesions posterior to the buccal space & \\
\hline Submandibular & Good access to lower buccal space & \\
\hline Paranasal & Good exposure & Facial nerve identification and dissection difficult \\
\hline Preauricular-suborbital & & Visible scar \\
\hline Parotid-submandibular & $\begin{array}{l}\text { Good exposure for addressing the neck, minimizes risk } \\
\text { of injury to facial nerve and Stenson's duct }\end{array}$ & Visible scar \\
\hline
\end{tabular}

areas extending beyond the tumor capsule carry a poor prognosis, the 5-year survival ranging from 25 to $65 \%{ }^{9}$ Hence they warrant an aggressive management. Our patient presented with a short history and had a well-circumscribed lesion which was unusual for a carcinoma ex pleomorphic adenoma. However, intracapsular carcinoma ex pleomorphic adenoma has been described. It is an exceedingly rare entity having a benign clinical behavior with metastatic unrecognized potential. The prognosis does not differ from that of benign mixed tumors when the malignant component is entirely contained within a fibrous capsule delimiting an otherwise benign pleomorphic adenoma. ${ }^{9}$ Although, a large series on malignant mixed tumors has reported no recurrences or metastasis in intracapsular carcinoma ex pleomorphic adenoma; there have been isolated case reports of regional metastasis from these tumors. ${ }^{8,10}$

The usual management of patients with carcinoma ex pleomophic adenoma involves a multimodality approach with surgical wide excision followed by adjuvant radiotherapy in view of the aggressive nature of the disease. Various surgical approaches have been described for lesions within the buccal space each with their advantages and drawbacks. The various approaches described by Rodgers and Myers et al (1988) have been tabulated (Table 1). ${ }^{11}$

Our patient too underwent wide excision which was amenable to an intraoral excision due to its proximity to the oral mucosa followed by adjuvant radiotherapy. It is known that intracapsular carcinoma ex pleomorphic adenoma has an excellent prognosis. ${ }^{9}$ Literature does not mention any management guidelines for such tumors. Considering the morbidity associated with adjuvant treatment, studies need to be performed to assess single modality treatment for such patients. However, in view of the rarity of this entity, large case series or randomized controlled trials would be difficult to perform.

\section{SUMMARY}

- Buccal space lesions are a diagnostic and therapeutic challenge.

- Intracapsular carcinoma ex pleomorphic adenoma is a rare entity especially within the buccal space.

- It occurs either in the accessory parotid gland or the minor salivary glands within the buccal space.

- It has a benign course with unrecognized malignant potential.

- There are no management guidelines for intracapsular carcinoma ex pleomorphic adenoma. Large case series and longer follow-ups are required to establish definitive management guidelines.

\section{REFERENCES}

1. Eneroth CM, Blanck C, Jakobsson PA. Carcinoma in pleomorphic adenoma of the parotid gland. Acta Otolaryngologica 1968;66:477-92.

2. Walvekar RR, Myers EN. Management of the mass in the buccal space. In: Salivary Gland Disorders, Edited by Myers EN, Ferris RL; Springer, Berlin Heidelberg, 2007;1:281-92.

3. Hyo-Cheol Kim, Moon Hee Han, Min Hoan Moon, Ji Hoon Kim, In: One Kim, Kee- Hyun Chang. CT and MR imaging of the Buccal Space: Normal Anatomy and Abnormalities. Korean J Radiol March 2005;6(1):22-30.

4. Smoker WRK. Oral cavity. In: Head and neck imaging, Edited by Som PM, Curtin HD (3rd ed). Mosby, St. Louis, 1996;488544.

5. Gnepp DR, Wenig BM. Malignant mixed tumors. In: Ellis G, Anclair P, Gnepp D, editors. Surgical pathology of the salivary glands. Philadelphia: Saunders; 1991;350-68.

6. Spiro RH, Huvos AG, Strong EW. Malignant mixed tumor of salivary origin: A clinicopathologic study of 146 cases. Cancer 1977;39:388-96. 
7. Leurs JC, Wittekindt C, Streppel M, Guntinas-Lichius O. Carcinoma ex pleomorphic adenoma of the parotid gland. Study and implications for diagnostics and therapy. Acta Oncol 2009;48(1):132-36.

8. LiVolsi VA, Perzin KH. Malignant mixed tumors arising in salivary glands. I. Carcinomas arising in benign mixed tumors: A clinicopathologic study. Cancer 1977;39:2209-30.
9. Gnepp DR. Malignant mixed tumors of the salivary glands: A review. Pathol Annu 1993;28:279-88.

10. Felix A, Rosa-Santos J, Mendonca ME, Torrinha F, Soares J. Intracapsular carcinoma ex pleomorphic adenoma. Report of a case with unusual metastatic behaviour. Oral Oncol 2002;38(1):107-10.

11. Rodgers GK, Myers EN. Surgical management of the mass in the buccal space. Laryngoscope 1988;98:749-53. 